\title{
Extrusión del esfínter artificial uretral externo. Caso clínico y revisión de la bibliografía
}

\author{
Arias-Zapien AS, Torres-Ochoa DE
}

Resumen

ANTECEDENTES: la prevalencia de incontinencia urinaria posterior a la prostatectomía radical se ha incrementado en los últimos años, debido al aumento de cirugías realizadas anualmente. La colocación del esfínter artificial uretral externo representa un método efectivo para el control de la incontinencia urinaria masculina, principalmente provocada por prostatectomía radical.

CASO CLÍNICO: paciente masculino de 70 años de edad, intervenido para prostatectomía radical, con incontinencia urinaria total. Después de la colocación del esfínter artificial uretral externo, acudió a consulta por dolor intenso en el escroto e inactivación del esfínter artificial; al cuarto mes posquirúrgico tuvo extrusión del dispositivo de la válvula por la bolsa escrotal. Se realizaron dos incisiones: una en la línea media suprapúbica para retirar el reservorio del esfínter artificial uretral externo y la otra en la línea media del rafe escrotal para retirar el dispositivo valvular extruido y el manguito localizado en la uretra bulbar. El paciente evolucionó sin complicaciones, se retiró el drenaje a las $72 \mathrm{~h}$ y la sonda de cistostomía al mes posquirúrgico. Hasta la fecha permanece sin complicaciones. El último estudio de control de antígeno prostático específico se efectuó en octubre de 2016, con concentración de $0.03 \mathrm{ng} / \mathrm{mL}$.

CONCLUSIONES: la válvula del esfínter artificial uretral externo debe colocarse en la bolsa escrotal, del lado dominante del paciente, lateral al cordón espermático y al testículo. El dominio de la técnica quirúrgica y la selección adecuada del paciente representan el factor determinante para el éxito de la cirugía.

PALABRAS CLAVE: esfínter, extruido, artificial, incontinencia, prostatectomía.
Rev Mex Urol. 2017 Nov-Dec;77(6):486-491.

\section{Artificial urinary sphincter extrusion. A case report and literature review}

Arias-Zapien AS, Torres-Ochoa DE

Abstract

BACKGROUND: The prevalence of incontinence after radical prostatectomy has increased in recent years due to the greater number of
Urólogo, Hospital Star Médica Lomas Verdes, Ciudad de México.

Recibido: enero 2017

Aceptado: noviembre 2017

Correspondencia

Dr. Alejandro Severo Arias Zapien

yemile158@gmail.com

Este artículo debe citarse como

Arias-Zapien AS, Torres-Ochoa DE. Extrusión del esfínter artificial uretral externo. Caso clínico y revisión de la bibliografía. Rev Mex Urol. 2017 nov-dic;77(6):486-491. DOI: https://doi.org/10.24245/revmexurol.v77i6.1212 
radical prostatectomies being performed annually. Artificial urinary sphincter placement is an effective method for controlling male urinary incontinence, especially when it results from radical prostatectomy.

CLINICAL CASE: A 70-year-old man had a past surgical history of radical prostatectomy that resulted in total urinary incontinence. After artificial urinary sphincter placement, he complained of intense pain in the scrotum, as well as inactivation of the artificial sphincter. Four months after the surgery, the patient presented with extrusion of the valve of the device through the scrotal sac. The reservoir of the artificial sphincter was removed through a suprapubic midline incision and the extruded valve and cuff located in the bulbar urethra were removed through an incision at the midline of the raphe. The patient progressed with no complications and the drain was removed at 72 $h$, followed by cystostomy catheter removal one month after the surgery. The last control prostate-specific antigen level was $0.03 \mathrm{ng} /$ $\mathrm{mL}$ in October 2016.

CONCLUSIONS: The artificial sphincter valve should be placed in the side of the scrotal sac corresponding to the patient's dominant hand, and lateral to the spermatic cord and testis. It should not be placed at the raphe. Mastery of the surgical technique and proper patient selection determine surgical success.

KEYWORDS Sphincter; Extrusion; Artificial; Urinary incontinence; Prostatectomy
Urólogo, Hospital Star Médica Lomas Verdes, Ciudad de México.

Correspondence

Dr. Alejandro Severo Arias Zapien yemile158@gmail.com

\section{ANTECEDENTES}

La prevalencia de incontinencia urinaria en hombres es de $39 \%$, incluso aumenta con la edad. ${ }^{1}$ La causa más frecuente de incontinencia urinaria de esfuerzo en hombres adultos se relaciona con prostatectomía radical, ${ }^{2}$ que representa el tratamiento de elección para el cáncer de próstata localizado..$^{1,2} \mathrm{El} 40 \%$ de los pacientes diagnosticados con cáncer de próstata prefieren la prostatectomía radical. ${ }^{3}$ La incontinencia urinaria posoperatoria es una de las principales complicaciones de la prostatectomía radical, con importante repercusión en la calidad de vida, pues su incidencia varía de 1 a 40\% de los casos. ${ }^{3}$ Debido al aumento de la prostatectomía radical efectuada en pacientes con cáncer de próstata, cada vez es mayor el número de ca- sos con incontinencia urinaria. ${ }^{2}$ A pesar de la efectividad de las técnicas quirúrgicas, la tasa de incontinencia urinaria varía de 5 a $48 \%,{ }^{1}$ y con el advenimiento de la cirugía robótica se ha estimado en 4 a $31 \% .^{2}$ Durante el primer año posquirúrgico, ${ }^{2}$ la colocación del esfínter uretral externo (un dispositivo de tratamiento) representa una buena alternativa para el tratamiento de la incontinencia urinaria masculina, por insuficiencia esfinteriana secundaria a la cirugía. En 1973, Scott y sus colaboradores reportaron el primer procedimiento de esfínter artificial. ${ }^{4-6}$ El modelo AS-742 fue el primer dispositivo con un balón regulador de presión, como reservorio líquido, que llenaba el manguito. La indicación más frecuente para su colocación es por complicaciones asociadas con la prostatectomía radical, en cuyos casos ha demostrado excelentes resultados. ${ }^{6,7}$ 
Los pacientes con incontinencia de origen neurógeno tienen mayor tasa de complicaciones y malos resultados, debido a las alteraciones de la vascularización y el trofismo tisular. ${ }^{8}$ Este procedimiento no está exento de complicaciones, pues se se han identificado: infección, ${ }^{2,8,9}$ rechazo, ${ }^{8}$ fístulas uretrales, ${ }^{8}$ estenosis, extrusión y malfuncionamiento valvular. ${ }^{8,9}$

\section{CASO CLÍNICO}

Paciente masculino de 70 años de edad, con antecedente de hipertensión arterial (en control médico), intervenido en julio de 2011 de prostatectomía radical retropúbica por cáncer de próstata localizado, con reporte histopatológico de adenocarcinoma acinar Gleason $(3+3)$, suma de Gleason 6, de $1 \times 0.9 \mathrm{~cm}$, que afectaba $20 \%$ del volumen prostático total. Los márgenes quirúrgicos resultaron negativos, sin invasión a las vesículas seminales, clasificado como T2bN0M0, por lo que no recibió tratamiento coadyuvante. El paciente padecía incontinencia urinaria permanente de mínimos esfuerzos al caminar, pararse, sentarse, toser o estornudar, con fuga de orina en su totalidad, por lo que no se llenaba su vejiga ni tenía deseo de micción, además de requerir el uso de pañales, colocación de un colector urinario externo y restricción de líquidos.

Se intervino quirúrgicamente en Monterrey, Nuevo León, en octubre de 2014, en donde se le colocó un esfínter artificial uretral externo para la corrección de la incontinencia urinaria (se desconoce la técnica quirúrgica implementada). Desde el posoperatorio inmediato refirió dolor intenso en el escroto, que nunca cedió, e inactivación del esfínter uretral, por lo que no podía orinar. En noviembre del mismo año le colocaron una sonda de cistostomía.

En diciembre de 2014 acudió al servicio de Urología del Hospital Star Médica Lomas Verdes por dolor intenso en el escroto (le impedía sentarse) y eritema en el área valvular. Continuó sin actividad del esfínter uretral, aún con la sonda de cistostomía para derivación. Al interrogatorio comentó que nunca le efectuaron estudios de urodinamia, solo 3 cistoscopias para evaluar la incontinencia urinaria.

El 25 de diciembre tuvo extrusión del dispositivo valvular por la bolsa escrotal (Figura 1), provocada por su localización anómala, lo que condicionó erosión y eritema. Se retiró completamente el dispositivo, se intervino el 27 de diciembre de 2014 (Figuras 2 y 3) y se prescribió ceftriaxona y amikacina.

Se realizaron dos incisiones: una en la línea media suprapúbica para retirar el reservorio del esfínter artificial uretral externo y la otra en la línea media del rafe escrotal para retirar el dispositivo valvular extruido y el manguito localizado en la uretra bulbar, que se encontraba

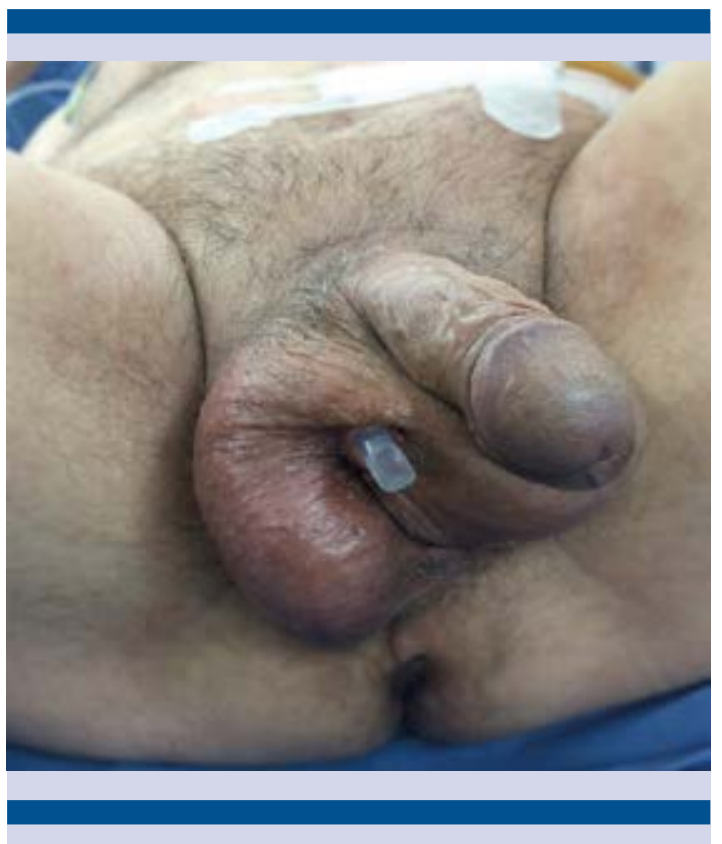

Figura 1. Válvula extruida del escroto, en el rafe, entre los testículos. 


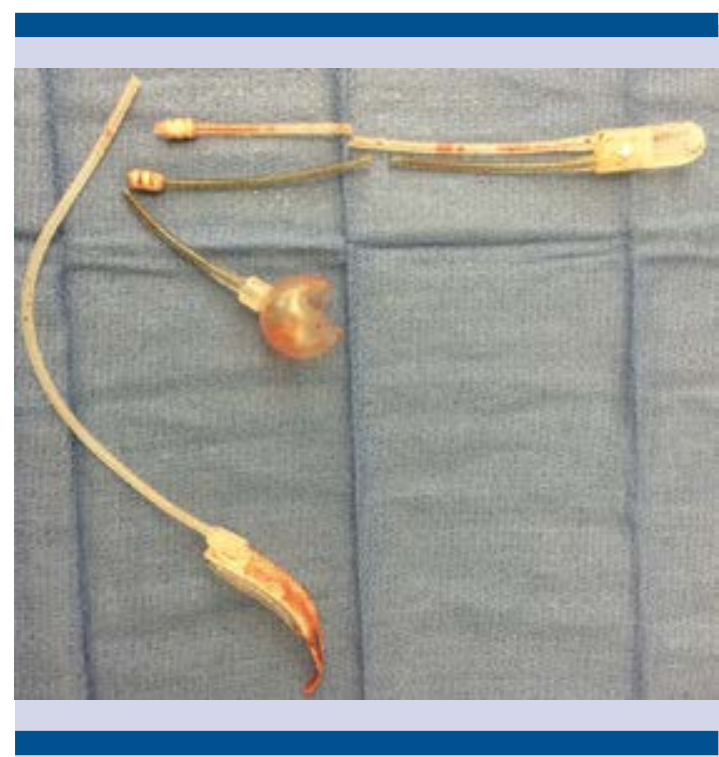

Figura 2. Esfínter uretral externo retirado en su totalidad.

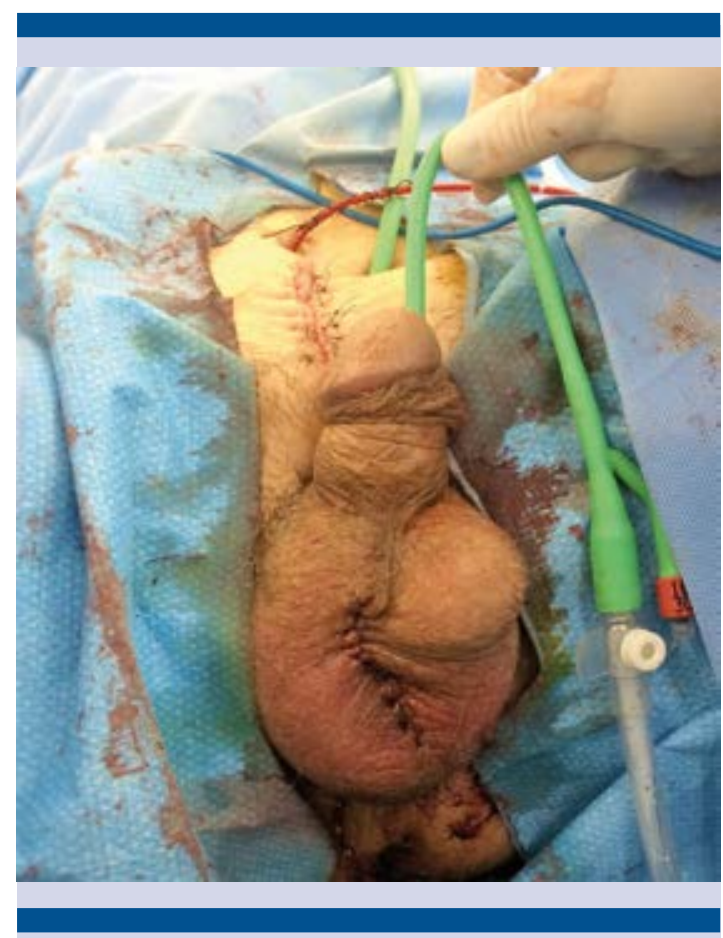

Figura 3. Reintervención quirúrgica (retiro completo de los dispositivos del esfínter uretral externo). desactivado y comprimiéndola al momento de la cirugía; por tanto, provocó que el manguito obstruyera la uretra desde la primera cirugía. EI paciente evolucionó sin complicaciones, se retiró el drenaje a las $72 \mathrm{~h}$ y la sonda de cistostomía al mes posquirúrgico. Hasta la fecha permanece con incontinencia urinaria, utiliza pañal, un colector urinario externo y se indicó restricción de líquidos; sin embargo, continúa sin complicaciones. El último estudio de control de antígeno prostático específico se efectuó en octubre de 2016, con concentración de 0.03 ng/mL.

\section{DISCUSIÓN}

La técnica correcta del esfínter uretral externo consiste en colocar la válvula en la bolsa escrotal, del lado de la mano dominante del paciente y no en el rafe. ${ }^{1,4,7} \mathrm{El}$ esfínter uretral externo funciona mejor en los pacientes motivados y dispuestos. Para obtener un buen resultado, la vejiga debe vaciarse completamente en lapsos determinados. Como en cualquier cirugía reconstructiva, es importante la preparación adecuada del paciente para llevar a cabo el procedimiento. Antes de la intervención quirúrgica deben efectuarse estudios completos de urodinamia, cistoscopia, urocultivo sin desarrollo bacteriano y prescripción de antibióticos profilácticos. La piel representa la fuente más probable de contaminación; ${ }^{8}$ en estos casos, Staphylococcus epidermidis es el principal agente patógeno.

\section{Técnica quirúrgica}

El manguito del esfínter artificial debe colocarse alrededor de la uretra bulbar. Al desactivar el manguito, debe tenerse cautela de no estrangular la uretra y permitir el paso de un catéter uretral de $16 \mathrm{Fr}$ sin problemas. El reservorio se coloca en la región inguinal, del lado dominante del paciente, por debajo de la fascia transversalis. ${ }^{7}$ Para la colocación de la bomba se diseca perfectamente la bolsa escrotal ipsilateral al reservorio, para- 
lelo al cordón espermático y el testículo, donde el paciente logre tocarlo fácilmente y cuando se mueva o se siente no le resulte incómodo (Figura 4). ${ }^{4}$ Todas las conexiones del dispositivo deben efectuarse por túneles en el tejido celular subcutáneo (Figura 5).

Las principales causas de extrusión de la válvula del esfínter se relacionan con: infecciones (4.5$67 \%),{ }^{2,8-10}$ antecedente de radioterapia, ${ }^{2}$ erosión por colocación inadecuada $(15 \%),{ }^{6-10}$ falla mecánica del manguito o la válvula (33\%), ,6,8-10 atrofia uretral ${ }^{2,6,9}$ y consumo de corticosteroides. ${ }^{11}$ La tasa de reintervención quirúrgica es de $26 \%$ (14.8-44.8\%). ${ }^{6}$ En el paciente de este estudio se colocó la válvula en la línea media del rafe, caudal a la bolsa escrotal; esto provocaba presión al momento de sentarse y posteriormente erosión de la piel, debido a que el manguito permaneció muy ajustado en la uretra bulbar; por tal motivo nunca pudo activarse la función del esfínter uretral externo, ni podía orinar a través de la uretra.

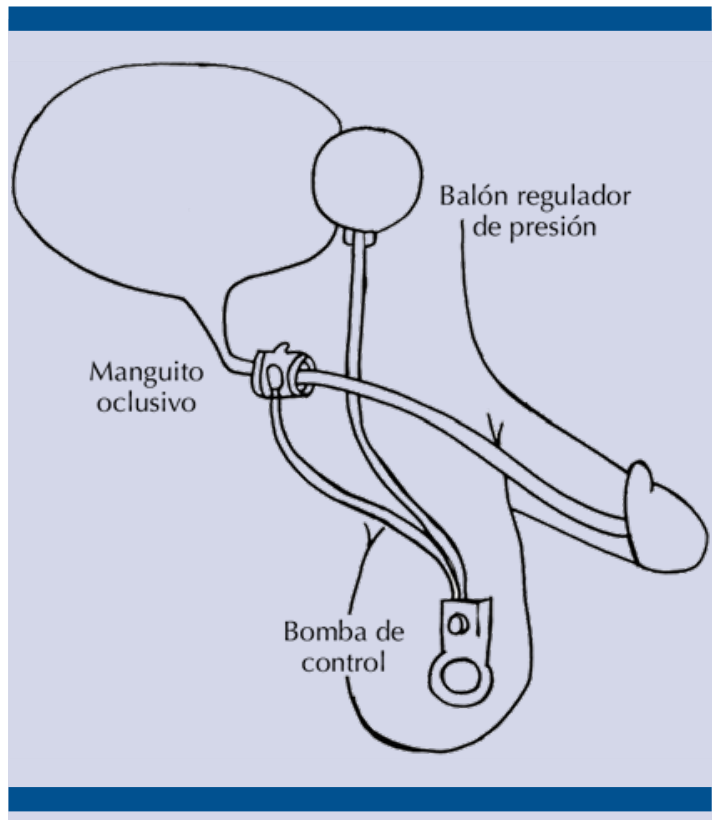

Figura 4. Colocación de los dispositivos del esfínter uretral externo; la válvula permanece lateralmente a los testículos, del lado dominante del paciente.

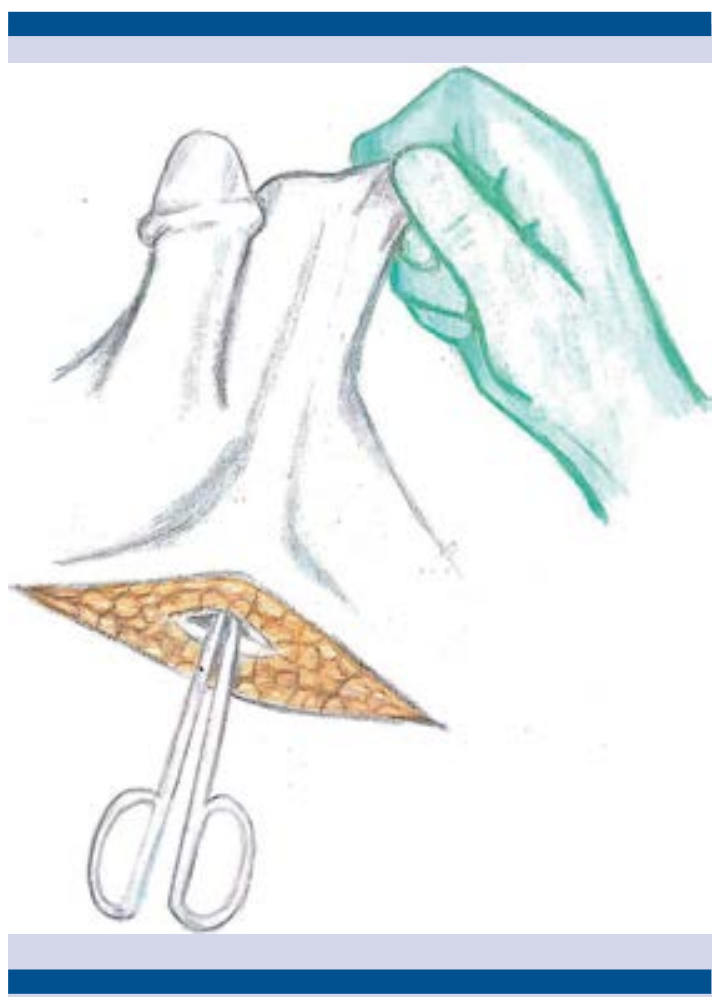

Figura 5. Túneles en el tejido celular subcutáneo para la colocación de dispositivos del esfínter uretral externo.

\section{CONCLUSIONES}

El esfínter uretral externo representa una excelente alternativa para el control de la incontinencia urinaria secundaria a la prostatectomía radical. Su tasa de éxito varía de 61 a 100\%, continencia de $79 \%$, periodo seco de 4 a $86 \%$ y satisfacción de 80 a 90\%. Es importante la selección adecuada del paciente, además de documentar el tipo de incontinencia urinaria mediante estudios completos de urodinamia, cistoscopia y cultivos negativos para obtener una mayor tasa de éxito. Todos los pacientes deben recibir antibióticos de amplio espectro antes del procedimiento quirúrgico. El éxito de la cirugía depende de la experiencia en la técnica quirúrgica, reflejada en el control de la incontinencia urinaria. 


\section{Fuente de financiamiento}

Los autores no recibieron ningún patrocinio para llevar a cabo este estudio.

\section{Conflicto de interés}

Los autores declaran no tener conflicto de interés.

\section{REFERENCIAS}

1. Bauera RM, Gozzib C, Hübnerc W, Nittid VW, et al. Contemporary management of postprostatectomy incontinence. Eur Urol 2011;59(6):985-996.

2. Cordon BH, Singla N, Singla AK. Artificial urinary sphincters for male stress urinary incontinence: current perspectives. Med Devices 2016;9:175-183.

3. Singla N, Singla AK. Post-prostatectomy incontinence: Etiology, evaluation, and management. Turk J Urol 2014;40(1):1-8.

4. Rodríguez-Escobar F, Araño-Bertran P. Incontinencia urinaria en el cáncer de próstata. Arch Esp Urol 2009;62(10):838-844.
5. Scott FB, Bradley WE, Timm GW, Kothari D. Treatment of urinary incontinence by implantable prosthetic sphincter. Urology 1973;1:252-9.

6. Van Der AF, Drake MJ, Petrolekas A, Cornu JN, et al. The artificial urinary sphincter after a quarter of a century: a critical systematic review of its use in male non-neurogenic incontinence. Eur Urol 2013;63(4):681-689.

7. Castaño-Botero J, Velásquez-Ossa J. Esfínter urinario artificial descripción de casos. Urol Colom 2009;18(3):63-68.

8. Sanz-Mayayo E, Gómez-García I, Fernández-Fernández E, et al. Esfínter artificial AMS-800. Nuestra experiencia en los últimos 20 años. Arch Esp Urol 2003;56(9):989-997.

9. García-Montes F, Gómez-Sancha F, Mundy A. El esfínter urinario artificial. Arch Esp Urol 2000;53(3):201-210.

10. Hussain M, Greenwell TJ, Venn SN, Mundy AR. The current role of the artificial urinary sphincter for the treatment of urinary incontinence. J Urol 2005;174:418-424.

11. Yap SA, Stone AR. Artificial urinary sphincter erosion: the role of corticosteroids in an unusual presentation. Can Urol Assoc J 2010;4(5):E144-145.

12. Montague DK, Angermeier KW, Paolone DR. Long-term continence and patient satisfaction after artificial sphincter implantation for urinary incontinence after prostatectomy. J Urol 2001;166(2):547-549.

\section{AVISO PARA LOS AUTORES}

Revista Mexicana de Urología tiene una nueva plataforma de gestión para envío de artículos: https://www.revisionporpares.com/index.php/RMUrol ahí podrá inscribirse a la base de datos administrada por el sistema Open Journal System (OJS) que ofrece las siguientes ventajas para los autores:

- Subir sus artículos directamente al sistema.

- Conocer, en cualquier momento, el estado de los artículos enviados, es decir, si ya fueron asignados a un revisor, aceptados con o sin cambios, o rechazados.

- Participar en el proceso editorial corrigiendo y modificando sus artículos hasta su aceptación final. 